\title{
Disease of the left main coronary artery: early surgical results and their association with carotid artery stenosis
}

\author{
W T Vigneswaran, R N Sapsford, R D L Stanbridge
}

\begin{abstract}
Objectives-To review the results of surgical revascularisation for left main coronary artery stenosis and the associated vascular pathology that is responsible for cerebrovascular complication.

Patients -60 patients ( 45 men, 15 women) (mean age 61.3 (39-79)) who underwent revascularisation for stenosis of the left main stem coronary artery (LMS) between January 1987 and August 1990 were compared with an age and sex matched control group of patients undergoing revascularisation for triple vessel disease during the same period.

Outcome measures-In-hospital morbidity and operative mortality.

Results-24 patients in the LMS group presented with unstable angina. The left ventricular ejection fraction was less than $50 \%$ in 30 patients and less than $30 \%$ in nine. 17 patients $(28 \%)$ had large vessel extracranial carotid artery disease and 10 patients had vascular disease of the lower limbs. In six patients atheromatous plaques were noted in the ascending aorta during surgery. There was no in-hospital mortality. In-hospital morbidity included neurological deficits in five $(8 \cdot 3 \%)$, arrhythmias in seven $(11.6 \%)$, and pulmonary complications in six $(10 \%)$ patients. The incidence of carotid artery disease in the LMS group was significantly higher $(p=0.04)$. Atheromatous plaque in the ascending aorta and postoperative neurological complications were more common patients with LMS.

Conclusions-The incidence of carotid artery disease was higher and postoperative cerebrovascular complications were more common in patients who had coronary artery revascularisation for stenosis of the left main stem coronary artery. The early surgical results were excellent. These findings suggest that for optimum perioperative management patients with stenosis of the left main coronary artery should be screened for carotid artery disease before bypass surgery.
\end{abstract}

(Br Heart f 1993;70:342-345)

Many studies have shown that patients with stenosis of the left main coronary artery have a poor outcome without coronary artery revascularisation. ${ }^{1-4}$ In the $1970 \mathrm{~s}$ it was reported that advanced age, female sex, unstable angina, congestive heart failure, decreased ejection fraction, high grade stenosis of the left main or right coronary artery, left dominant circulation, and emergency surgery increased the perioperative mortality. ${ }^{56}$ An analysis a decade later showed that female sex, emergency surgery, and left main stenosis of $>80 \%$ in patients with a left dominant or balanced circulation were the only significant factors in perioperative and long-term mortality. ${ }^{7}$ The techniques of cardiopulmonary bypass, coronary artery revascularisation, and myocardial protection have steadily improved over the past two decades. This, and the improvements in perioperative monitoring and intensive care has increased the scope and safety of cardiac surgery. In the 1990 s the success of an operation for stenosis of the left main stem coronary artery or for any type of cardiac surgery should be measured not only by the mortality but also by the morbidity associated with the treatment.

Despite the improved mortality for coronary artery revascularisation, the cerebrovascular complications remain important. ${ }^{9-12}$ Certain pre-existing disease processes in the patient predispose to cerebrovascular complications. Carotid artery stenosis, atheromatous plaques in the proximal aorta, and intracardiac thrombus all have a role in the development of stroke after cardiopulmonary bypass surgery. ${ }^{1314}$ Awareness of pre-existing disease and technical modification of the operative procedure perhaps will reduce the incidence of this devastating complication. Since the middle of 1986 we have examined systematically the carotid arteries and lower limb vessels before surgery and have recorded the state of the aorta at operation in all patients undergoing coronary artery revascularisation. During this period we noted that the incidence of cerebrovascular complications was higher in patients with disease of the left main coronary artery (LMS). Therefore we reviewed the records of all patients undergoing revascularisation for LMS and an age and sex matched group of patients undergoing revascularisation for triple vessel coronary artery stenosis not affecting the left main coronary artery (non-LMS) between January 1987 and August 1990 to determine whether carotid artery disease and atheroma of the ascending aorta were associated with an increase in operative morbidity and mortality. 
Patients and methods

Nine hundred patients underwent isolated coronary artery revascularisation at our hospital between January 1987 and August 1990 . In a subgroup of 60 patients revascularisation was performed for stenosis of the left main coronary artery caused by atheromatous disease. This group formed the basis of this retrospective review. Sixty patients in the remaining group of 840 were selected as a control group. They had undergone revascularisation for triple vessel disease and were matched for year of operation, age, and sex with the group with stenosis of the left main coronary artery. The following clinical variables were analysed in all patients: age; sex; New York Heart Association (NYHA) functional class; presence or absence of unstable angina; previous myocardial infarction; incidence of hypertension, diabetes mellitus, and hyperlipidaemia; urgency of operation, presence of carotid artery disease, lower limb arterial disease, and atheromatous disease in the ascending aorta; and the early postoperative results. Coronary angiography was performed in all patients and reviewed by the referring cardiologist and the operating surgeon.

\section{EVALUATION OF CAROTID ARTERY DISEASE}

In all patients the carotid arteries were systematically examined during the initial referral and at admission for operation. Patients with a carotid bruit were investigated initially with carotid ultrasound and Doppler scan. If the scan indicated narrowing of the extracranial carotid artery patients were additionally evaluated. by intravenous or arterial digital subtraction angiography (IVDSA/IADSA) or a carotid artery angiogram. The arterial stenosis on the angiogram was estimated visually as the percentage loss of luminal cross sectional area.

The consultant cardiologist and cardiac surgeon jointly made the decision to proceed with coronary artery revascularisation. Carotid artery endarterectomy was deemed to be necessary if carotid artery stenosis was symptomatic, if the stenosis was associated with evidence of cerebral infarct on a computed tomogram, or if there was severe stenosis $(>70 \%)$. The combined operation was performed in patients with significant LMS and in those with no LMS disease but with unstable angina or poor left ventricular function (EF $<40 \%)$. The decision was made jointly at the neurocardiovascular conference.

\section{SURGICAL TECHNIQUE}

The technique for coronary artery revascularisation involved aortic and right atrial cannulation and mild systemic hypothermic cardiopulmonary bypass $\left(28^{\circ} \mathrm{C}\right)$. The mean perfusion pressure was kept above $60 \mathrm{~mm} \mathrm{Hg}$ for patients with carotid artery disease and above $40 \mathrm{~mm} \mathrm{Hg}$ in the remainder. Complete revascularisation of the heart was attempted in all patients. The internal mammary artery was used for coronary revascularisation whenever possible. The distal anastomosis was per- formed first with aortic cross clamping (except where there was calcification or heavy atheroma of the ascending aorta) and the proximal anastomosis was performed while heart was being reperfused.

When the carotid artery endarterectomy was combined with coronary artery revascularisation, the endarterectomy was performed before cardiopulmonary bypass. The saphenous vein was prepared during this time. At the end of carotid endarterectomy, the neck was packed with a povidone iodine soaked sponge while coronary artery revascularisation was performed. Haemostasis in the neck was checked after cardiopulmonary bypass was stopped and systemic heparinisation was reversed. Then the wound was closed.

All patients were transferred to the intensive care unit immediately after operation and were given intermittent positive pressure ventilation.

STATISTICAL ANALYSIS

The $\chi^{2}$ test and the test for comparison of proportions were used to compare both groups of patients. A p value of $<0.05$ was regarded as statistically significant.

\section{Results}

There were 45 men and 15 women in each group. The mean age was 61.3 years (range 39-79) in the LMS group and 60.5 years (range 40-77) in the non-LMS group. The clinical variables for both groups were not significantly different (table 1 ).

Twenty four patients with LMS disease presented with unstable angina. The left ventricular ejection fraction was $<50 \%$ in half the patients with LMS stenosis, whereas it was $<50 \%$ in 47 of patients (78\%) without LMS. The ejection fraction was less than $30 \%$ in nine patients with LMS stenosis and in eight patients with non-LMS stenosis. The coronary artery was dominant on the left side in 11 patients with LMS stenosis and in three with non-LMS stenosis; it was dominant on the right side in 46 patients with LMS stenosis and in 52 patients with non-LMS stenosis. Forty nine patients in the LMS group had luminal narrowing of $>50 \%$ in both the right and left coronary arteries. In 37 patients the left coronary artery lumen was narrowed by $>80 \%$ (table 2).

Table 1 Clinical variables before revascularisation in patients with stenosis of the left main coronary artery and in patients without

\begin{tabular}{lll}
\hline Clinical variables & LMS $(n)$ & Non LMS (n) \\
\hline Mean age (yr) & $61 \cdot 3$ & $60 \cdot 5$ \\
Previous MI & 33 & 44 \\
Hypertension & 22 & 32 \\
Hyperlipidaemia & 21 & 18 \\
Diabetes mellitus & 10 & 13 \\
Unstable angina & 24 & 15 \\
NYHA class: II & 3 & 1 \\
III & 21 & 32 \\
IV & 36 & 27 \\
Urgent emergency operation & $33^{\star}$ & $15^{\star}$ \\
Mean grafts/patient & $4 \cdot 15$ & $3 \cdot 83$ \\
\hline
\end{tabular}

MI, myocardial infarction. ${ }^{\star} \mathrm{p}=0.002$. 
Table 2 Angiographic luminal narrowing of the left main and right coronary arteries in the group with stenosis of the left main coronary artery

\begin{tabular}{lc}
\hline Stenosis type & No \\
\hline Left coronary stenosis: & \\
Ostial & 7 \\
Luminal >80\% & 37 \\
Luminal 50-80\% & 23 \\
Right coronary stenosis: & \\
Luminal >80\% & 40 \\
Luminal 50-80\% & 9 \\
Luminal 0-50\% & 11 \\
\hline
\end{tabular}

There was stenosis of the extracranial carotid arteries in $17(28 \%)$ patients with LMS stenosis but only in seven patients with non-LMS stenosis $(p=0.04)$. Fifteen patients in the LMS group showed $>50 \%$ luminal narrowing of one or more of the extracranial carotid arteries. Three patients in each group underwent a carotid endarterectomy before coronary artery revascularisation. Ten patients in the LMS group and 11 patients in the non-LMS group presented with symptomatic lower limb arterial disease.

A significantly higher number of patients with LMS stenosis underwent urgent or emergency revascularisation $(p=0.002)$. A mean of $4 \cdot 15$ coronary artery bypass grafts per patient were performed in the LMS group and 3.83 coronary grafts per patient were performed in the non-LMS group. Use of the internal mammary artery was similar in both groups (50\% in the LMS group and $53 \%$ in the non-LMS group for the whole period, but an internal mammary artery graft was used in $90 \%$ of the patients during the last 12 months of the series). Five patients in the LMS group underwent a combined carotid endarterectomy and coronary artery revascularisation compared with only one patient in the nonLMS group. At the time of coronary artery revascularisation atheromatous plaque was seen in the ascending aorta in six patients in the LMS group and in three patients in the non-LMS group ( $p=$ NS) (table 3 ).

There were no hospital deaths among the patients undergoing revascularisation for LMS disease but one patient in the group with non-LMS disease died of multi-organ failure secondary to low cardiac output syndrome. The median postoperative hospital stay was 8 days for both groups. In one patient in LMS group postoperative pulmonary embolism developed and he was in hospital for 47 days. The incidence of cerebrovascular complications was higher in the LMS group than in the non-LMS group. Table 3 shows the major postoperative

Table 3 Vascular pathology and postoperative complications

\begin{tabular}{|c|c|c|c|c|c|c|}
\hline \multirow[b]{2}{*}{ Group } & \multicolumn{3}{|l|}{ Disease } & \multicolumn{3}{|c|}{ Complications } \\
\hline & Carotid & Lower limb & Plaque* & Pulmonary & CNS & Arrhythmia \\
\hline $\begin{array}{l}\text { LMS } \\
\text { TVD }\end{array}$ & $\begin{array}{r}17(3) \dagger \\
7(3) \dagger\end{array}$ & $\begin{array}{l}10 \\
11\end{array}$ & $\begin{array}{l}6 \\
3\end{array}$ & $\begin{array}{l}6 \\
5\end{array}$ & $\begin{array}{l}5(8 \cdot 3 \%) \\
2(3 \cdot 3 \%)\end{array}$ & $\begin{array}{r}7 \\
11\end{array}$ \\
\hline
\end{tabular}

*In the ascending aorta. Left main coronary artery stenosis (LMS) and non-LMS, triple vessel coronary artery stenosis (TVD).

tp $=0.04$. Numbers in parentheses are patients who had staged carotid artery endarterectomy. complications in both groups. There was no significant difference in the postoperative complications between the groups. One patient in the LMS group with a postoperative neurological defect did not have extracranial carotid artery disease.

\section{Discussion}

We found that carotid artery disease was quite common in our patients. Postoperative cerebrovascular complications were more common in patients with stenosis of the left main stem coronary artery who were undergoing revascularisation.

The mechanisms of cerebral complication during coronary artery revascularisation are complex. Causes proposed include embolisation from atheromatous plaques in the aorta or the extracranial carotid and vertebral arteries. Breuer et al reported a considerable incidence of stroke in patients with $>5 \%$ diameter stenosis of the carotid arteries who were undergoing coronary artery revascularisation. ${ }^{15}$ Mortality was also increased (up to $14.3 \%$ ) in patients with carotid artery diameter stenosis of $>50 \%{ }^{15-17}$ However, a policy of screening the extracranial carotid arteries of all patients undergoing coronary artery revascularisation may not be justified owing to the low incidence, the cost of the technique, and the equivocal benefit of prophylactic carotid artery endarterectomy. ${ }^{18-22}$ Attention to perfusion pressure and flow during cardiac surgery and careful haemodynamic management during the postoperative period is essential in patients with carotid artery disease to reduce cerebral complication.

Stroke related to aortic atheromatous disease is well recognised by cardiac surgeons but not often reported in the literature. ${ }^{23} \mathrm{As}$ the age of the population undergoing cardiac surgery increases so does awareness of this problem. Simple palpation of the aorta has been the standard technique of recognising atheromatous plaque but more complex techniques such as epicardial echocardiography and biplane transoesophageal echocardiography can accurately diagnose this condition before operation. ${ }^{24-26}$ The techniques are not widely used but should be available in future to screen patients and plan the surgical technique during cardiac surgery. Alternative arterial cannulation and avoidance of aortic clamping is likely to reduce the incidence of embolisation of atheromatous material when there is atheromatous disease in the aorta. Furthermore, modification of the grafting technique to include sequential distal anastomosis and use of arterial grafts with pedicles may be indicated to reduce aortic manipulation.

We did not show a relation between the high incidence of carotid artery disease or the presence of aortic atheromatous plaques and stroke after coronary artery revascularisation. None the less it is likely that these factors played an important part in the evolution of stroke in these patients. In this series one patient in whom a cerebral complication 
developed did not have any carotid artery disease but he had atheromatous disease of the ascending aorta.

Despite an increase in atherosclerotic disease of the carotid arteries and atheromatous plaques of the ascending aorta in the LMS group (the triad) the incidence of peripheral vascular disease was similar to that in nonLMS group. We cannot explain this finding. We believe, however, that information on extracranial carotid artery disease and on the state of the ascending aorta is important to optimum results after coronary artery revascularisation in patients with LMS. Vascular ultrasound can be used to evaluate accurately extracranial carotid artery disease and the state of the ascending aorta. We believe that patients presenting with disease of the left main stem coronary artery should be screened for carotid artery disease and aortic atheromatous plaques.

1 Takaro T, Hultgren HN, Lipton MJ, Detre KM, and Participants in the Study Group. The VA Cooperative randomized study of surgery for coronary arterial occlusive disease. II. Subgroup with significant left main lesions. Circulation 1976;54(suppl III): 107-17.

2 European Coronary Surgery Study Group: Prospective randomised study of coronary artery bypass surgery in stable angina pectoris. Lancet 1980;ii:491-5.

3 Chaitman BR, Fisher LD, Bourassa MG, Davis K, Rogers WJ, Maynard C, et al. Effect of coronary bypass surgery on survival patterns in subsets of patients with left main coronary artery disease. Report of the Collaborative

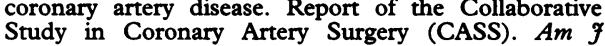
Cardiol 1981;48:765-77.

4 Coles JC, Goldbach MM, Ahmed SN, Wells GA, Mehta HV. Left main-stem coronary artery disease: Surgical versus medical management. Can $\mathcal{F}$ Surg 1984;27:571-3.

5 Jeffery DL, Vijayanagar R, Bognolo DA, Eckstein PF, Spoto E Jr, Natarajan P, et al. Surgical treatment of 200 consecutive patients with left main coronary artery disease. Ann Thorac Surg 1983;36:193-201.

6 Chaitman BR, Rogers WJ, Davis K, Tyras DH, Berger R, Bourassa MG, et al. Operative risk factors in patients
with left main coronary-artery disease. $N$ Engl $₹$ Med 1980;303:953-7.

7 Gomberg J, Klein LW, Seelaus P, Parr GVS, Agarwal JB, Helfant RH. Surgical revascularization of left main coronary artery stenosis: Determinants of perioperative and long-term outcome in the 1980s. Am Heart $\mathcal{f}$ and long-term $688 ; 116: 440-6$.
8 Contini GA, Barboso G, Contini SA, Medici D, Fesani F. Surgical treatment of left main coronary stenosis. $\dot{f}$ Cardiovasc Surg 1987;28:638-41.

9 Tufo HM, Ostfeld AM, Shekelle R. Central nervous system dysfunction following open-heart surgery. $\mathfrak{F} A M A$ 1970;212:1333-40.

10 Branthwaite MA. Neurologic damage related to openheart surgery. Thorax 1972;27:748-53.

11 Savageau JA, Stanton B, Jenkins CD, Klein MD. Neuropsychological dysfunction following elective cardiac operation: I. Early assessment. ₹ Thorac Cardiovasc diac operation: I. Early
Surg 1982;84:585-94.

12 McGrath LB, Laub GW, Graf D, Gonzalez-Lavin L. Hospital death on a cardiac surgical service: negative influence of changing practice patterns. Ann Thorac Surg 1990;49:410-2.

13 Faggioli GL, Curl GR, Ricotta JJ. The role of carotid screening before coronary artery bypass. $\mathcal{f}$ Vasc Surg 1990;12:724-31.

14 Gardner TJ, Horneffer PJ, Manolio TA, Pearson, TA, Gott VL, Baumgartner WA, Borkon AM, Watkins L Jr, Reitz BA. Stroke following coronary artery bypass grafting: A ten-year study. Ann Thorac Surg 1985;40:574-81.

15 Breuer AC, Franco I, Marzewski D, Soto-Velasco J. Left ventricular thrombi seen by ventriculography are a sigventricular thrombi seen by ventriculography are a sig-
nificant risk factor for stroke in open heart surgery. Ann nificant risk factor for

16 Craven TE, Ryu JE, Espeland MA, Kahl FR, McKinney, WM, Toole JF, McMahan MR, Thompson CJ, Heiss G, Crouse JR III. Evaluation of the associations between carotid artery atherosclerosis and coronary artery stenosis. Circulation 1990;82:1230-42.

17 Balderman SC, Gutierrez IZ, Makula P, Bhayana JN, Gage AA. Noninvasive screening for asymptomatic carotid artery disease prior to cardiac operation. $\mathcal{F}$ Thorac Cardiovasc Surg 1985;85:427-33.

18 Foster AH, Salter DR. Cerebral pathophysiologic considerations in patients with coexisting carotid and coronary artery disease. In: Karp RB, Laks H, Wechsler AS, eds. artery disease. In: Karp RB, Laks H, Wechsler AS, eds.
Advances in cardiac surgery. St Louis: Mosby Year Advances in cardiac

19 Perler BA, Burdick JF, Minken SL, Williams GM. Should we perform carotid endarterectomy synchronously with cardiac surgical procedures? ₹ Vasc Surg 1988;8:402-9.

20 Jones EL, Craver JM, Michalik RA, Murphy DA, Guyton RA, Bone DK, Hatcher CR, Reichwald NA. Combined carotid and coronary operations: When are they necessary? $₹$ Thorac Cardiovasc Surg 1984;87:7-16.

21 Hart RG, Easton JD. Management of cervical bruits and carotid stenosis in preoperative patients. Stroke 1983;14 290-7.

22 Hertzer NR, Loop FD, Beven EG, O'Hara PJ, Krajewski LP. Surgical staging for simultaneous coronary and carotid disease: A study including prospective randomcarotid disease: A study including pro

23 Blauth CI, Webb B, Ratliff NB, Lytle BW, Loop FD, Cosgrove DM. Atheroembolism from the ascending Cosgrove DM. Atheroembolism from the ascending aorta: An emerging problem in cardiac
Cardiovasc Surg 1992;103:1104-11.

24 Marshall WG Jr, Barzilai B, Kouchoukos NT, Saffitz J. Intraoperative ultrasonic imaging of the ascending aorta. Ann Thorac Surg 1989;48:339-44.

25 Tunick PA, Kronzon I. The association between protruding plaques in the thoracic aorta and systemic embolization [abstr]. $\mathcal{F}$ Am Coll Cardiol 1991;17:261.

26 Wareing TH, Davila-Roman VG, Barzilai B, Murphy SF, Kouchoukos NT. Management of the severely atherosclerotic aorta during cardiac operations: A strategy for detection and treatment. $\mathcal{F}$ Thorac Cardiovasc Surg 1992;103:453-62 